\title{
Use of Penalized Count Regression to Determine Factors Affecting the Length of Stay of Trauma Patients in the Intensive Care Unit
}

\author{
Zahra Shayann ${ }^{1,}$, Shahram Paydar², Fatemeh Maghsoudi ${ }^{3}$, Ali Taheri Akerdi² ${ }^{2}$ and Leila Shayan ${ }^{2}$ \\ 1Department of Biostatistics, Trauma Research Center, School of Medicine, Shiraz University of Medical Sciences, Shiraz, Iran \\ 2Trauma Research Center, Rajaee (Emtiaz) Trauma Hospital, Shiraz University of Medical Sciences, Shiraz, Iran \\ ${ }^{3}$ Department of Biostatistics, School of Medicine, Shiraz University of Medical Sciences, Shiraz, Iran. Abadan Faculty of Medical Sciences, Abadan, Iran
}

* Corresponding author: Zahra Shayan, Department of Biostatistics, Trauma Research Center, School of Medicine, Shiraz University of Medical Sciences, Shiraz, Iran. Tel: 07132084301; Email: shayanz@sums.ac.ir

Received 2021 August 16; Revised 2021 September 11; Accepted 2021 0ctober 11.

\begin{abstract}
Background: Trauma is considered an important issue in most countries. Identification of the factors affecting the length of stay (LOS) in the intensive care unit (ICU) plays a crucial role in controlling the costs and complications of prolonged hospitalization.

Objectives: This study aimed to identify the factors affecting the LOS of trauma patients in the ICU using stepwise and new penalized variable selection methods in count data regression.

Methods: The patients' information was evaluated in Emtiaz Hospital and Shahid Rajaee trauma center in Shiraz from March 2016 to September 2017. Count regression model was used to determine the factors affecting the LOS of patients in the ICU using penalized variable selection including, Enet, Snet, and Mnet.

Results: The mean age of the patients $(n=382)$ was obtained at $36.7 \pm 16.7$ years, and the majority (88.4\%) of the patients were male. The mean LOS in the ICU was determined at $6.2 \pm 6.6$ days. Mnet with a negative binomial distribution outperformed the other penalized variable selection methods. A Glasgow Coma Scale (GCS) of less than 9 (IRR=1.7), blunt brain trauma (IRR=1.8), chest trauma (IRR=2.2), and oxygen saturation of less than 90 (IRR=1.2) increased the LOS of trauma patients in the ICU.

Conclusion: Penalized variable selection methods effectively ignore or control the existing correlations between predictors. Amongst the penalized models, Mnet provided more acceptable results with smaller Akaike information criterion and fewer predictors. According to this penalty, the most important factors affecting the length of stay were chest trauma, blunt brain trauma, GCS, and oxygen saturation rate. Most clinical studies on trauma have also shown the importance of these factors.
\end{abstract}

Keywords: ICU, LOS, Penalized variable selection, Trauma

\section{Background}

Trauma is the fourth leading cause of death worldwide and the first cause of death in the first four decades of life (1). Currently, about $50 \%$ of traumas in the world are related to traffic accidents, and according to the World Health Organization, this will rise to $60 \%$ in 2020 if no major measures are implemented (2)

Trauma imposes direct and indirect economic and social burdens on communities. Therefore, healthcare policymakers should take fundamental measures to reduce such costs $(1,3)$, especially those resulting from an unexpected increase in the length of stay (LOS) (4). In addition to the loss of human and hospital resources (bed occupancy, medication, and device use) and depreciation of medical equipment, prolonged LOS increases the likelihood of various infections, which is considered a risk factor for increased mortality (5). Several factors, such as age, disease history, injury severity, and clinical complications, including coagulopathy, thromboembolism, and renal failure are involved in increasing the LOS of trauma patients.(6)

Different statistical methods, such as linear and generalized regression have been used in the literature to investigate variables affecting the LOS of trauma patients (6-8). The use of linear regression for count data leads to inconsistent standard deviations. The LOS is commonly considered count data with a highly skewed distribution due to some patients' stay in hospital for a long time. Therefore, Poisson and Negative Binomial (NB) regression are used for analyzing such data $(9,10)$.

Variable selection is frequently used to reduce large important predictors and obtain a more interpretable model. Traditionally, it has been performed using backward, forward, and stepwise methods (11). These methods are unstable and sometimes computationally intensive when the numbers of predictors grow. Furthermore, due to the high correlation among these predictors, conventional classical methods perform inefficiently in such cases, leading to an increase in the variance and a decrease in the estimation accuracy (9). For these reasons, recently, penalized variable selection has gained more attention in data analysis. These methods are more robust than classical ones.

New methods, such as the least absolute shrinkage and selection operator (LASSO) (12), adaptive LASSO (13), smoothly clipped absolute deviation (SCAD) (14), and the minimum concave penalty $(\mathrm{MCP})(15,16)$ are used to model selection and coefficients estimation simultaneously. However, some recent methods have been proposed, especially 
for count data, such as Elastic net (Enet), as well as MCP, and SCAD for the generalized linear model, including Poisson regression, the mixture of MCP and ridge penalty (Mnet), and the mixture of SCAD and ridge penalty (Snet) $(9,17,18)$. The Enet, Mnet, and Snet penalties have the advantage of selecting highly correlated predictors. Moreover, these methods have been extended to the penalized NB regression in recent years (9).

\section{Objectives}

The present study aimed to determine the predictor variables of the LOS of trauma patients in the intensive care unit (ICU) using stepwise and new penalized variable selection methods in count data regression. To our knowledge, this is one of the earliest studies to investigate the factors associated with LOS using these new methods.

\section{Methods}

\subsection{Study design}

This prospective observational study investigated the records of trauma patients referred to the Cardio Pulmonary Resuscitation room of Emtiaz Hospital and Shahid Rajaee trauma center from March 2016 to September 2017 and then admitted to the ICU .

\subsection{Participants}

The required data were extracted from the patients' medical files by trained staff. The files included patients' demographic characteristics, as well as clinical and laboratory data. Records of patients over 16 years with a complete record of admission in the ICU for at least one day were included in the study. Patients who expired or those with incomplete records were excluded from the study.

\subsection{Variables}

The number of days upon ICU admission to discharge was considered the response variable and demographic characteristics, as well as clinical and laboratory findings, were independent variables. Due to the variety of patients being admitted to trauma ICU, they were classified into three categories of blunt trauma with brain injury, blunt trauma without brain injury, and penetrating trauma with and without brain injury.

\subsection{Statistical analysis}

The methods of Wang et al. were used for this section (9). Let random variable $Y$ follow a Poisson distribution with a single parameter $\mu$ when mean $=$ variance $=\mu$. In real data, overdispersion often occurs when variance is larger than mean. In these cases, NB distribution may be used as a better model.
Let $\log (\mu)=x_{i}{ }^{T} \beta(i=1,2 \ldots, n)$, where $\beta=\left(\beta_{0}, \beta_{1}, \ldots\right.$, $\left.\beta_{\mathrm{p}}\right)^{\mathrm{T}}$, $\mathrm{p}$ is the number of variables, and $\beta_{0}$ signifies the intercept.

For variable selection, consider a penalized loglikelihood function:

$p l(\beta ; y)=l(\beta ; y)-n \sum_{j=1}^{p} p\left(\lambda ;\left|\beta_{j}\right|\right)$

where $1(\beta ; y)$ is the log-likelihood function of Poisson or NB distribution, and $p\left(\lambda ;\left|\beta_{\mathrm{j}}\right|\right)$ presents the penalty function with tuning parameter $\lambda$. With maximizing, the equation (1) can estimate parameters and shrink small coefficients to zero. In this study, three penalty functions are used as follows:

i. The Enet penalty

$$
p\left(\lambda_{1}, \lambda_{2} ;|\beta|\right)=\lambda_{1}|\beta|+\frac{1}{2} \lambda_{2} \beta^{2}
$$

For $\lambda_{1}$ and $\lambda_{2} \geq 0$.

ii. The Mnet penalty

$$
\begin{aligned}
& p\left(\lambda_{1}, \lambda_{2} ;|\beta|\right)=p\left(\lambda_{1} ;|\beta|\right)+\frac{1}{2} \lambda_{2} \beta^{2} \\
& p\left(\lambda_{1} ; \beta\right)^{T}=\left(\lambda_{1}-\frac{\beta}{\gamma}\right) I\left(\beta \leq \gamma \lambda_{1}\right)
\end{aligned}
$$

$$
\text { For } \lambda_{1} \text { and } \lambda_{2} \geq 0 \text { and } \gamma>1 \text {. }
$$

iii. The Snet penalty

$$
\begin{aligned}
& p\left(\lambda_{1}, \lambda_{2} ;|\beta|\right)=p\left(\lambda_{1} ;|\beta|\right)+\frac{1}{2} \lambda_{2} \beta^{2} \\
& p\left(\lambda_{1} ; \beta\right)^{T}=\lambda_{1}\left\{I\left(\beta<\lambda_{1}\right)+\frac{\left(\gamma \lambda_{1}-\beta\right)_{+}}{(\gamma-1) \lambda_{1}} I\left(\beta \geq \lambda_{1}\right)\right\}
\end{aligned}
$$

For $\lambda_{1}$ and $\lambda_{2} \geq 0$ and $\gamma>2$.

The parameters have been estimated with a combination of the iteratively reweighted leastsquares algorithm and coordinate descent algorithm. The 10-fold cross-validation was used to estimate the tuning parameters .

In the penalized method, the coefficient is determined for a significant variable; otherwise, a zero coefficient is considered, and a p-value is not reported. Our findings were interpreted using the incidence rate ratio (IRR=ecoefficient); moreover, Akaike information criterion (AIC) and Bayesian information criterion (BIC) indices were used to select the best model. The variables were selected by the stepwise method using Stata software (version 12). The penalized variable selection, including Enet, Mnet, and Snet was carried out by an R package named "mpath" in R software $(6,19)$. The standard error cannot be estimated directly in the penalized methods; therefore, the Bootstrap method with 500 iterations was used to estimate the standard error of the coefficients. 


\section{Results}

\subsection{Demographic and mechanism of injury characteristics}

A total of 382 medical records that met the inclusion criteria were evaluated in this study. The mean age of the patients was $36.7 \pm 16.7$ years (age range: $16-93$ years, and $8.1 \%$ of the patients had age above 65 years), and $88.4 \%$ of the patients were male $(\mathrm{n}=342)$; moreover, the injuries included head injury (38.7\%), neck injury (5\%), chest injury (4.5\%), abdomen injury (16\%), pelvis injury $(15.7 \%)$, spine injury $(6.3 \%)$, and extremities injury $(28.5 \%)$. A mean Injury Severity Score (ISS) of $7.3 \pm 10.9$ was obtained (75.4\% of the patients had an ISS over 15$)$ in this study, and most of the patients $(69.3 \%)$ had Glasgow Coma Scale (GCS) $>12$ (mild) (Table 1). Descriptive characteristics of the vital signs and laboratory data are described in Tables 2 and 3. The mean LOS in the ICU was $6.2 \pm 6.6$ days ( 1 to 43 days with a median of 4 days). The distribution of LOS suggested that the common linear regression was not valid (Figure 1). Considering unequal mean and variance of the Poisson distribution, it is clear that the NB distribution was appropriate than the Poisson distribution for the LOS modeling.

\subsection{Results of penalized variable selection}

The results of regression modeling are presented in Table 4. According to the results obtained from the stepwise selection method, oxygen (02) saturation, a GCS of less than 9, head and chest injury, blood urea nitrogen (BUN), Partial Thromboplastin Time (PTT), and blunt trauma with brain injury were identified as variables affecting the LOS in the ICU. The Mnet method outperformed the Snet and Enet penalty with smaller AIC and BIC. However, the Mnet and Snet penalties were similar in the number of less significant predictors. The results of the Mnet penalty can be interpreted as follows. A GCS less than 9 was significant in this model indicating a 70\% increase in the length of stay in the ICU (IRR=1.7). Chest injury

\begin{tabular}{|c|c|c|c|c|}
\hline Independent variables & $\mathrm{N}=382$ Count & Percent & Mean LOS \pm SD (days) & P-value $^{*}$ \\
\hline \multicolumn{5}{|l|}{ Age (year) } \\
\hline$\geq 65$ & 31 & 8.1 & $5.2 \pm 5.4$ & \multirow{2}{*}{0.34} \\
\hline$<65$ & 351 & 91.9 & $6.4 \pm 6.7$ & \\
\hline \multicolumn{5}{|l|}{ Gender } \\
\hline Male & 337 & 88.2 & $6.3 \pm 6.6$ & \multirow[t]{2}{*}{0.97} \\
\hline Female & 45 & 11.8 & $6.2 \pm 6.5$ & \\
\hline \multicolumn{5}{|l|}{ Trauma mechanism } \\
\hline Penetrating trauma & 20 & 5.2 & $3.1 \pm 2.4$ & \multirow{3}{*}{0.002} \\
\hline Blunt trauma with brain injury & 328 & 85.9 & $6.7 \pm 6.9$ & \\
\hline Blunt trauma without brain injury & 34 & 8.9 & $3.6 \pm 3.2$ & \\
\hline \multicolumn{5}{|l|}{ GCS } \\
\hline 3-8 (severe) & 61 & 16.0 & $10.1 \pm 8.4$ & \multirow{3}{*}{$<0.001$} \\
\hline $9-12$ (moderate) & 77 & 20.2 & $6.8 \pm 6.7$ & \\
\hline$>12$ (mild) & 244 & 63.9 & $5.2 \pm 5.7$ & \\
\hline \multicolumn{5}{|l|}{ Head injury } \\
\hline Yes & 148 & 38.7 & $7.5 \pm 7.2$ & \multirow[t]{2}{*}{0.004} \\
\hline No & 234 & 61.3 & $5.5 \pm 6.1$ & \\
\hline \multicolumn{5}{|l|}{ Neck injury } \\
\hline Yes & 19 & 5.0 & $6.7 \pm 7.5$ & \multirow{2}{*}{0.78} \\
\hline No & 363 & 95.0 & $6.2 \pm 6.6$ & \\
\hline \multicolumn{5}{|l|}{ Chest injury } \\
\hline Yes & 17 & 4.5 & $14.1 \pm 11.8$ & \multirow[t]{2}{*}{$<0.001$} \\
\hline No & 356 & 95.5 & 5. $9 \pm 6.1$ & \\
\hline \multicolumn{5}{|l|}{ Abdomen injury } \\
\hline Yes & 61 & 16.0 & $5.9 \pm 5.7$ & \multirow[t]{2}{*}{0.69} \\
\hline No & 321 & 84.0 & $6.3 \pm 6.8$ & \\
\hline \multicolumn{5}{|l|}{ Pelvis injury } \\
\hline Yes & 60 & 15.7 & $6.4 \pm 6.2$ & \multirow[t]{2}{*}{0.83} \\
\hline no & 322 & 84.3 & $6.2 \pm 6.7$ & \\
\hline \multicolumn{5}{|l|}{ Spine injury } \\
\hline Yes & 24 & 6.3 & $5.1 \pm 3.6$ & \multirow[t]{2}{*}{0.35} \\
\hline No & 358 & 93.7 & $6.3 \pm 6.8$ & \\
\hline \multicolumn{5}{|l|}{ Extremities injury } \\
\hline Yes & 109 & 28.5 & $6.3 \pm 6.9$ & \multirow[t]{2}{*}{0.87} \\
\hline No & 273 & 71.5 & $6.2 \pm 6.5$ & \\
\hline \multicolumn{5}{|l|}{ ISS } \\
\hline$>15$ & 288 & 75.4 & $5.8 \pm 6.3$ & \multirow[t]{2}{*}{0.01} \\
\hline$\leq 15$ & 94 & 24.6 & $7.7 \pm 7.3$ & \\
\hline
\end{tabular}

* The p-value was obtained based on an independent t-test or one-way ANOVA.

GCS: Glasgow Coma Scale

ISS: Injury Severity Score 


\begin{tabular}{|c|c|c|c|c|}
\hline Independent variables & $\begin{array}{c}\mathrm{N}=382 \\
\text { Count }\end{array}$ & Percent & Mean LOS \pm SD (days) & P-value* \\
\hline \multicolumn{5}{|l|}{ PR (number) } \\
\hline$>100$ & 164 & 42.9 & $6.8 \pm 7.2$ & 0.18 \\
\hline$\leq 100$ & 218 & 57.1 & $5.9 \pm 6.2$ & \\
\hline \multicolumn{5}{|l|}{ RR (number) } \\
\hline$>20$ & 102 & 26.7 & $7.3 \pm 8.2$ & 0.07 \\
\hline$\leq 20$ & 280 & 73.3 & $5.9 \pm 5.9$ & \\
\hline \multicolumn{5}{|l|}{ SBP (mmHg) } \\
\hline$\geq 90$ & 18 & 5.0 & $5.9 \pm 6.0$ & $<0.001$ \\
\hline$<90$ & 364 & 95.0 & $13.3 \pm 11.9$ & \\
\hline \multicolumn{5}{|l|}{ DBP (mmHg) } \\
\hline$<60$ & 32 & 8.4 & $7.0 \pm 7.0$ & 0.51 \\
\hline$\geq 60$ & 350 & 91.6 & $6.2 \pm 6.6$ & \\
\hline \multicolumn{5}{|l|}{02 sat (percent) } \\
\hline$<90$ & 83 & 21.7 & $8.6 \pm 8.5$ & $<0.001$ \\
\hline$\geq 90$ & 299 & 78.3 & $5.6 \pm 5.9$ & \\
\hline
\end{tabular}

* The p-value was obtained based on an independent T-test.

PR: Pulse Rate; RR: Respiratory Rate; SBP: Systolic Blood Pressure; DBP, Diastolic Blood Pressure; 02sat: 02 Saturation

\begin{tabular}{|c|c|c|c|c|}
\hline Independent variables & $\mathrm{N}=382$ Count & Percent & Mean LOS \pm SD (days) & P-value* \\
\hline $\begin{array}{l}\text { Serum (litter) } \\
>2 \\
\leq 2\end{array}$ & $\begin{array}{c}63 \\
319\end{array}$ & $\begin{array}{l}16.5 \\
83.5\end{array}$ & $\begin{array}{l}6.0 \pm 5.9 \\
6.3 \pm 6.8\end{array}$ & 0.73 \\
\hline $\begin{array}{l}\text { BUN (mg/dl) } \\
>20 \\
\leq 20\end{array}$ & $\begin{array}{c}59 \\
323\end{array}$ & $\begin{array}{l}15.4 \\
84.6\end{array}$ & $\begin{array}{l}8.3 \pm 8.6 \\
5.9 \pm 6.1\end{array}$ & 0.009 \\
\hline $\begin{array}{l}\text { Cr (mg/dl) } \\
\quad>1.2 \\
\quad \leq 1.2\end{array}$ & $\begin{array}{c}83 \\
299\end{array}$ & $\begin{array}{l}21.7 \\
78.3\end{array}$ & $\begin{array}{l}6.8 \pm 6.9 \\
6.1 \pm 6.5\end{array}$ & 0.44 \\
\hline $\begin{array}{l}\text { Na (meq/lit) } \\
<135 \text { and }>145 \\
\text { others }\end{array}$ & $\begin{array}{c}57 \\
325\end{array}$ & $\begin{array}{l}14.9 \\
85.1\end{array}$ & $\begin{array}{l}6.1 \pm 6.4 \\
6.3 \pm 6.7\end{array}$ & 0.86 \\
\hline $\begin{array}{l}\text { K (meq/lit) } \\
<3.5 \text { and }>5 \\
\text { others }\end{array}$ & $\begin{array}{c}63 \\
319\end{array}$ & $\begin{array}{l}16.5 \\
83.5\end{array}$ & $\begin{array}{l}7.7 \pm 7.7 \\
6.0 \pm 6.4\end{array}$ & 0.07 \\
\hline $\begin{array}{l}\text { FBS }(\mathbf{m g} / \mathbf{d l}) \\
\quad>180 \\
\leq 180\end{array}$ & $\begin{array}{c}78 \\
304\end{array}$ & $\begin{array}{l}20.4 \\
79.6\end{array}$ & $\begin{array}{l}8.0 \pm 8.7 \\
5.8 \pm 5.9\end{array}$ & 0.008 \\
\hline $\begin{array}{l}\text { PT (second) } \\
>15 \\
\leq 15\end{array}$ & $\begin{array}{c}33 \\
349\end{array}$ & $\begin{array}{c}8.6 \\
91.4\end{array}$ & $\begin{array}{l}8.4 \pm 6.9 \\
6.1 \pm 6.6\end{array}$ & 0.049 \\
\hline $\begin{array}{l}\text { INR } \\
>1.3 \\
\leq 1.3\end{array}$ & $\begin{array}{c}80 \\
302\end{array}$ & $\begin{array}{l}20.9 \\
79.1\end{array}$ & $\begin{array}{l}7.6 \pm 7.4 \\
5.9 \pm 6.4\end{array}$ & 0.046 \\
\hline $\begin{array}{l}\text { PTT (second) } \\
>45 \\
\leq 45\end{array}$ & $\begin{array}{c}15 \\
367\end{array}$ & $\begin{array}{c}3.9 \\
96.1\end{array}$ & $\begin{array}{l}3.9 \pm 2.8 \\
6.4 \pm 6.7\end{array}$ & 0.17 \\
\hline $\begin{array}{l}\text { WBC }\left(\mathbf{m m}^{\mathbf{3}}\right) \\
\quad \geq 1100 \\
<1100\end{array}$ & $\begin{array}{l}278 \\
104\end{array}$ & $\begin{array}{l}72.8 \\
27.2\end{array}$ & $\begin{array}{l}6.6 \pm 7.1 \\
5.3 \pm 5.2\end{array}$ & 0.08 \\
\hline $\begin{array}{l}\text { HB (g/dl) } \\
\quad<10 \\
\geq 10\end{array}$ & $\begin{array}{c}34 \\
348\end{array}$ & $\begin{array}{c}8.9 \\
91.1\end{array}$ & $\begin{array}{l}7.4 \pm 7.6 \\
6.2 \pm 6.5\end{array}$ & 0.29 \\
\hline $\begin{array}{l}\text { PH } \\
<7.35 \text { and }>7.45 \\
\text { others }\end{array}$ & $\begin{array}{l}192 \\
190\end{array}$ & $\begin{array}{l}50.3 \\
49.7\end{array}$ & $\begin{array}{l}7.1 \pm 7.4 \\
5.4 \pm 5.6\end{array}$ & 0.011 \\
\hline $\begin{array}{l}\text { PCO2 }(\mathbf{m m H g}) \\
<35 \text { and }>45 \\
\text { others }\end{array}$ & $\begin{array}{l}220 \\
162\end{array}$ & $\begin{array}{l}57.6 \\
42.4\end{array}$ & $\begin{array}{l}6.3 \pm 6.9 \\
6.1 \pm 6.1\end{array}$ & 0.77 \\
\hline $\begin{array}{l}\text { BE } \\
<-6 \\
\geq-6\end{array}$ & $\begin{array}{c}53 \\
329\end{array}$ & $\begin{array}{l}13.9 \\
86.1\end{array}$ & $\begin{array}{l}7.5 \pm 6.6 \\
6.1 \pm 6.6\end{array}$ & 0.13 \\
\hline $\begin{array}{l}\text { HCO3 }(\mathrm{meq} / \mathrm{L}) \\
\quad<20 \\
\geq 20\end{array}$ & $\begin{array}{c}82 \\
300\end{array}$ & $\begin{array}{l}21.5 \\
78.5\end{array}$ & $\begin{array}{l}6.7 \pm 6.1 \\
6.2 \pm 6.8\end{array}$ & 0.54 \\
\hline $\begin{array}{l}\text { HCT (perent) } \\
\quad<30 \\
\geq 30 \\
\end{array}$ & $\begin{array}{c}36 \\
346\end{array}$ & $\begin{array}{c}9.4 \\
90.6\end{array}$ & $\begin{array}{l}7.9 \pm 7.6 \\
6.1 \pm 6.5\end{array}$ & 0.109 \\
\hline
\end{tabular}

* The p-value was obtained based on an independent T-test.

BUN: Blood Urea Nitrogen; Cr: Creatinine; Na: Sodium; K: Potassium; INR: International Normalized Ratio; WBC: White Blood Cell; PH: Potential Hydrogen; PCO2: Partial Pressure Of Carbon Dioxide; FBS: Fasting Blood Sugar; HB: Hemoglobin; HCT: Hematocrit; BE: Base Excess 


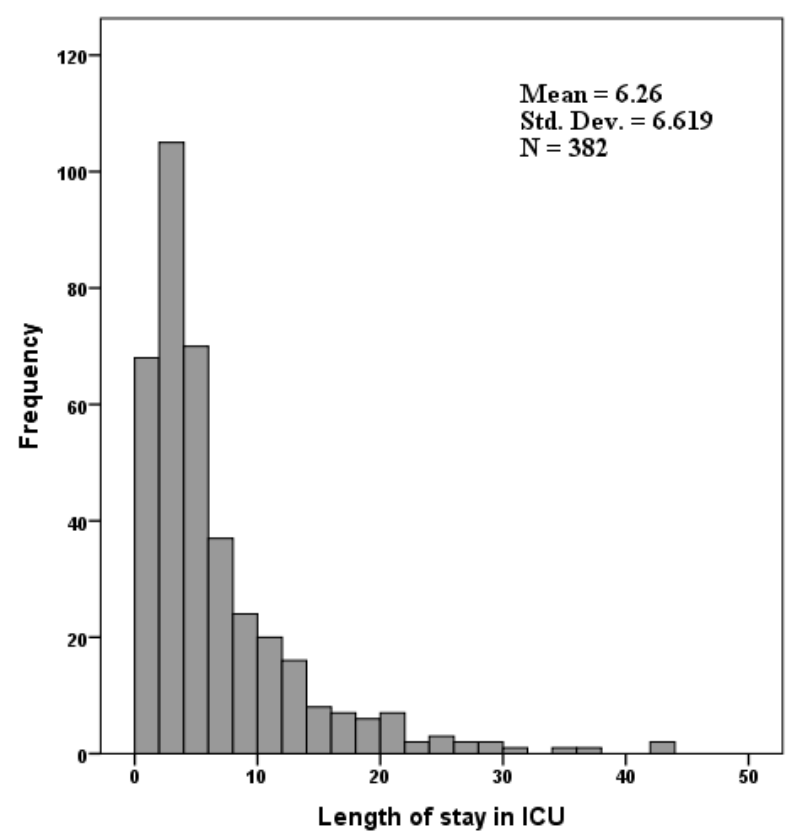

Figure 1. Distribution of hospital stay of trauma patients in the ICU

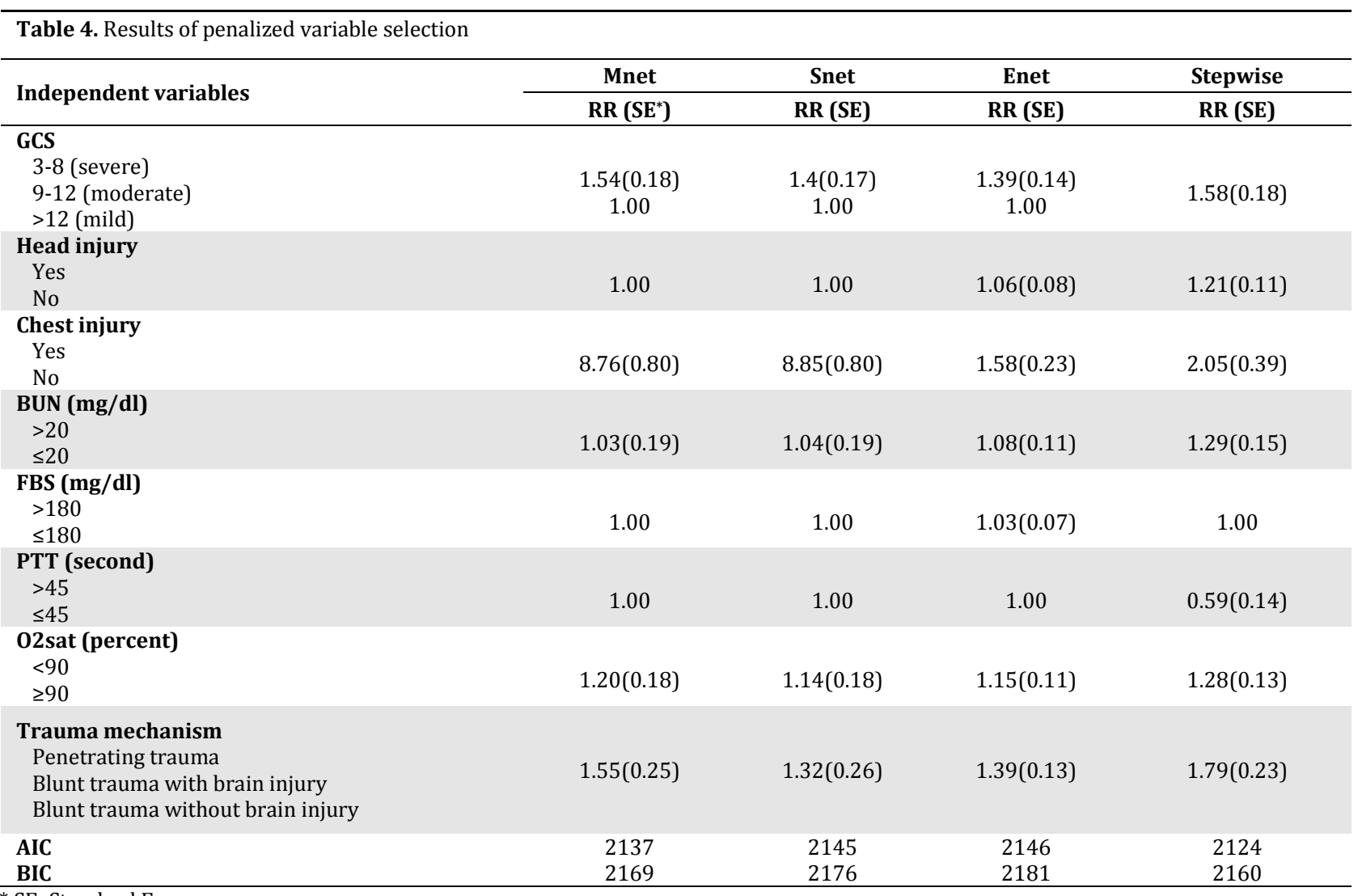

* SE: Standard Error

BUN: Blood Urea Nitrogen; PTT: Partial Thromboplastin Time; PT: Prothrombin Time; SE: Standard Error; AIC: Akaike Information Criterion; BIC: Bayesian; 02sat: 02 Saturation

was another significant predictor that prolonged the expected length of stay in the ICU by 2.2 days $(I R R=2.2)$. The length of stay of the blunt trauma patients with brain injury approximately increased by
1.8 times than those with blunt trauma without brain injury (IRR=1.8) indicating an almost $80 \%$ increase in the LOS. The LOS increased up to $20 \%$ in patients with an 02 saturation of less than $90 \%$ (IRR=1.2). 


\section{Discussion}

This study aimed at determining the predictor variables of the LOS of trauma patients using stepwise and penalized variable selection methods in the count regression model. According to the results, a GCS of less than 9, blunt brain trauma, chest injury, and 02 saturation of less than $90 \%$ caused an increase in the LOS of trauma patients in the ICU.

The NB regression model was used to identify the factors affecting the LOS of trauma patients in the ICU of Emtiaz Hospital and Shahid Rajaee trauma center. Most studies on the LOS in the ICU were performed through linear regression or logistic regression (6-7). Due to a large number of predictors and the possibility of significant correlation between them, the penalized variable selection methods were used to determine the important predictors instead of stepwise methods. The selection of variables by the stepwise method is dependent on the value of the type I error (10). Enet, Mnet, and Snet penalized variable selection methods were used to overcome the collinearity problem. There is no need to assess the collinearity assumption using these methods, and all variables can be considered in the model (9).

Wang et al. (2016) studied pediatric cardiac surgery data to determine factors resulting in acute kidney injury and an increase in the length of stay. To this end, they used the penalized variable selection methods in Poisson count regression and NB models. According to their results, the penalized NB model outperformed the Poisson count regression model [9]. The results of this study also confirmed the reasonable performance of these models.

The GCS which indicates the severity of brain injury was significant in all methods. According to the results, a GCS of less than 9 increased the LOS in the ICU by $70 \%$. As it was found in other studies (6-7, 20-22), the LOS decreases with increasing GCS. As another key variable, blunt trauma with brain injury was significant in all methods. Blunt trauma with brain injury includes motorbike accidents, pedestrian accidents, car accidents, falls from altitude, accidents, and falling down. Our results showed that LOS in blunt trauma patients with brain injury increased 1.8 times more than that in those without this trauma.

In a study in the United States (2011), Glance et al. investigated the relationship among the complications of prolonged stay in trauma patients and found a direct relationship of the mechanism of trauma with increased LOS and its complications (23). Chest injury was also a significant variable in the present study. Patients with chest injury stayed in the ICU approximately 3 days more than those without this type of trauma. This increased LOS can impose a significant burden of cost on the health system as well as families and can be associated with complications, such as infection. Therefore, LOS reduction can decrease the risk of death due to such infections (6). In this regard, Glance et al. showed that patients with chest injury are at a greater risk of complications and prolonged stay, compared to those without chest injury (23).

Blood 02 saturation was another significant variable so that an 02 saturation of less than $90 \%$ increased the LOS up to $20 \%$. There are few studies on the relationship of this variable with LOS in the ICU, and most studies pertained to the death of trauma patients (24). Although PTT is considered a significant variable in the classical methods, it is an insignificant variable in the penalized methods. Shaz et al. also found no relationship between PTT and LOS in their studies (25). The strength of the present study was the use of a new variable selection for the count regression model recently introduced. However, a key limitation to this investigation was the incomplete medical files. The results of this study can be used to decrease the LOS for future planning.

\section{Conclusion}

According to the results, the penalized variable selection methods with an NB distribution were more suitable to determine the factors affecting the length of stay in the ICU. These methods effectively ignore or control the existing correlations between variables. Amongst the penalized models, Mnet provided more acceptable results with smaller AIC and fewer predictors. According to the results, GCS, blunt trauma, chest injury, and 02 saturation were identified as variables affecting the LOS in the ICU. Identification and control of factors affecting the length of stay can predict hospitalization costs that are imposed on both the patient and the government and can also help to allocate optimal resources.

\section{Acknowledgments}

This study was extracted from a thesis by Fatemeh Maghsoudi for the degree of Master of Science at Shiraz University of Medical Sciences, Shiraz, Iran. The authors wish to thank H. Argasi at the Research Consultation Center of Shiraz University of Medical Sciences for his invaluable assistance in editing this manuscript.

\section{Footnotes}

Authors' contributions: ZSH and FM contributed to the study conception, implementation of the study, design, data analysis, interpretation, and critical drafting of the manuscript. SHP and AT were involved in drafting and revising the manuscript. $\mathrm{LSH}$ contributed to the collection of data and design. All authors have read and approved the manuscript and ensure that this is the case. 
Ethical Approval: The patient's information was in private. All information was collected only by the patient's code, and their identity was not disclosed. This study was conducted and approved by the local Ethics Committee of Shiraz University of Medical Sciences, Shiraz, Iran (IR.SUMS.REC.1396.S871).

Funding/Support: This study was financially supported by Shiraz University of Medical Sciences, Shiraz, Iran (grant No. 15496).

Conflicts of Interest: The authors declare that they have no competing interests.

\section{References}

1. Texas Department of Health. Trauma Registry Overview USA; 2002. P. 1 Available from: www.tdh.State.tx.us.Accessed 2003.

2. Krug EG, Sharma GK, Lozano R. The global burden of injuries. Am J Public Health. 2000;90(4):523-26. doi: 10.2105/ajph.90.4.523. [PubMed: 10754963].

3. Siletz A, Jin K, Cohen M, Lewis C, Tillou A, Cryer HM, et al. Emergency department length of stay in critical nonoperative trauma. J Surg Res. 2017;214:102-8. doi:10.1016/j.jss. 2017.02.079. [PubMed: 28624030].

4. Moore L, Stelfox HT, Turgeon AF, Nathens A, Bourgeois G, Lapointe J, et al. Hospital Length of Stay After Admission for Traumatic Injury in Canada: A Multicenter Cohort Study. Injury. 2014;260(1): 179-87. doi: 10.1097/SLA.0000000000000624. [PubMed: 27839794].

5. Chaudhary MA, Schoenfeld AJ, Tracey P. Koehlmoos TP, Cooper $\mathrm{Z}$, Haider AH, et al. Prolonged ICU stay and its association with 1-year trauma mortality :An analysis of 19,000 American patients. Am J Surg. 2019;218(1):21-26. doi: 10.1016/j.amjsurg.2019.01.025. Epub. [PubMed: 30722934].

6. Böhmer AB, Just KS, Lefering R, Paffrath T, Bouillon B, Joppich $\mathrm{R}$, et al. Factors influencing lengths of stay in the intensive care unit for surviving trauma patients: a retrospective analysis of 30,157 cases. Crit Care. 2014;18(4):R143. doi: 10.1186/cc13976. [PubMed: 25001201].

7. Moore L, Stelfox HT, Turgeon AF, Nathens AB, Lavoie A, Émond $M$, et al. Derivation and validation of a quality indicator of acute care length of stay to evaluate trauma care. Ann Surg. 2014;260(6):1121-27. doi: 10.1097/SLA.0000000000000648. [PubMed: 24743606].

8. Dvorak MF, Noonan VK, Fallah N, Fisher CG, Finkelstein J, Kwon BK, et al. The influence of time from injury to surgery on motor recovery and length of hospital stay in acute traumatic spinal cord injury: an observational Canadian cohort study. $J$ neurotraum. 2015;32(9):645-54. doi: 10.1089/neu.2014.3632. [PubMed: 25333195].

9. Wang Z, Ma SH, Zappitelli M, Parikh C, Wang C-Y, Devarajan P, et al. Penalized count data regression with application to hospital stay after pediatric cardiac surgery. Stat Methods Med Res. 2016;25(6):2685-703. doi: 10.1177/0962280214530608. [PubMed: 24742430].
10. Wang Z, Ma SH, Wang C-Y, Zappitellid M, Devarajane P, Parikh Ch, et al. EM for Regularized Zero Inflated Regression Models with Applications to Postoperative Morbidity after Cardiac Surgery in Children. Stat Med. 2014; 33(29): 5192-5208. doi: 10.1002/sim.6314. [PubMed: 25256715].

11. Miller A. Subset selection in regression. Chapman and Hall/CRC. 2002

12. Tibshirani R. Regression shrinkage and selection via the lasso. $J$ $R$ Statist Soc B. 1996; 58:267-288. doi: 10.1111/j.25176161.1996.tb02080.x.

13. Zou H. The adaptive lasso and its oracle properties. J Am Statist Ass. 2006; 101:1418-1429. doi: 10.1198/016214506000000735.

14. Fan J, Li R. Variable selection via nonconcave penalized likelihood and its oracle properties. J Am Statist Ass. 2001; 96:1348-1360. doi: 10.1198/016214501753382273.

15. Zou H. ,Hastie T. Regularization and variable selection via the elastic net. $J R$ Statist Soc B. 2005; 67:301-320. doi:10.1111/j.1467-9868.2005.00503.x.

16. Zhang CH. Nearly unbiased variable selection under minimax concave penalty. Ann Stat. 2010; 38:894-942. doi: 10.1214/09-A0S729.

17. Friedman J, Hastie T, Tibshirani R. Regularization paths for generalized linear models via coordinate descent. J Stat Software. 2010; 33:1-22.[PubMed: 20808728].

18. Fan J, Lv J. Nonconcave penalized likelihood with NPdimensionality. IEEE Transact Inform Theory. 2011;57(8):54675484. doi: 10.1109/TIT.2011.2158486.

19. Wang Z. mpath: Regularized Linear Models. R package version 0.2-4. 2014:1-89.

20. Cowen TD, Meythaler JM, Michael J, Ivie III CS, Lebow J, Novack TA, et al. Influence of Early Variables in Traumatic Brain Injury on Functional Independence Measure Scores and Rehabilitation Length of Stay and Charges. Arch Phys Med Rehabil. 1995;76(9):797-803. doi: 10.1016/s0003-9993(95)80542-7 . [PubMed: 7668948].

21. High Jr WM, Hall KM, Rosenthal M, Mann N, Zafonte R, Cifu DX, et al. Factors affecting hospital length of stay and charges following traumatic brain injury. J Head Trauma Rehabil. 1996;11(5):85-96.

22. Kamravan HR, Haghnegahdar A, Paydar S, Khalife M, Sedighi M Ghaffarpasand F, et al. Epidemiological and clinical features of cervical column and cord injuries; a 2-year experience from a large trauma center in Southern Iran. Bull Emerg Trauma. 2014;2(1):32-37.[PubMed: 27162861].

23. Glance LG, Stone PW, Mukamel DB, Dick AW. Increases in mortality, length of stay, and cost associated with hospitalacquired infections in trauma patients. Arch Surg. 2011; 146(7):794-801. doi:10.1001/archsurg.2011.41. [PubMed: 21422331].

24. Salehpoor F , Meshkini A, Shokouhi G, Aghazade J, Lotfinia I, Shakeri M, et. al. Prognostic serum Factors in Traumatic Brain Injury: A Systematic Review. Iran J Neurosurg. 2015, 1(1): 10-22.

25. Shaz B, Winkler A, James A, Hillyer C, MacLeod J. Pathophysiology of early trauma-induced coagulopathy: emerging evidence for hemodilution and coagulation factor depletion. J Trauma. 2011;70(6):1401-7. doi: 10.1097/TA.0b013e31821266e0. [PubMed: 21460741]. 